\title{
The sample processing time interval as an influential factor in flow cytometry analysis of lymphocyte subsets
}

\author{
Ana Paula dos Santos, Álvaro Luiz Bertho*, Reinaldo de Menezes Martins**, \\ Rugimar Marcovistz/ ${ }^{+}$
}

Laboratório de Tecnologia Imunológica **Assessoria Clínica e Médica, Biomanguinhos-Fiocruz *Laboratório de Imunoparasitologia, Departamento de Imunologia, Instituto Oswaldo Cruz-Fiocruz, Av. Brasil 4365, 21045-900 Rio de Janeiro, RJ, Brasil

The objective of this paper is to propose a protocol to analyze blood samples in yellow fever 17DD vaccinated which developed serious adverse events. We investigated whether or not the time between sample collection and sample processing could interfere in lymphocyte subset percentage, for it is often impossible to analyze blood samples immediately after collection due to transport delay from collection places to the flow cytometry facility.

$C D 4^{+} C D 38^{+} T, C D 8^{+} C D 38^{+} T, C D 3^{+} T, C D 19^{+} B$ lymphocyte subsets were analyzed by flow cytometry in nine healthy volunteers immediately after blood collection and after intervals of 24 and $48 \mathrm{~h}$. The whole blood lysis method and gradient sedimentation by Histopaque were applied to isolate peripheral blood mononuclear cells for flow cytometry analyses. With the lysis method, there was no significant change in lymphocyte subset percentage between the two time intervals $(24$ and $48 \mathrm{~h})$. In contrast, when blood samples were processed by Histopaque gradient sedimentation, time intervals for sample processing influenced the percentage in $T$ lymphocyte subsets but not in B cells. From the results obtained, we could conclude that the whole blood lysis method is more appropriate than gradient sedimentation by Histopaque for immunophenotyping of blood samples collected after serious adverse events, due to less variation in the lymphocyte subset levels with respect to the time factor.

Key words: yellow fever - flow cytometry - lymphocyte subsets

Yellow fever (YF) remains a serious health problem in endemic areas of tropical and subtropical Africa and South America (Vasconcelos 2003). Approximately 90\% of the infected people have mild infections or are asymptomatic, while $10 \%$ develop severe morbidness leading to $50 \%$ case-fatality. In Brazil, this illness can be prevented through YF 17DD virus substrain vaccine, which induces protective neutralizing antibodies of long duration.

Although the YF 17DD substrain is one of the most successful vaccines ever elaborated, rare cases of serious postvaccinal disorders have been recorded (Vasconcelos et al. 2001). The virus isolates from two post YF 17DD vaccination fatal cases demonstrated genetic stability and attenuated phenotype, suggesting that some immune defense peculiarities of the host might have been responsible for such adverse events (Galler et al. 2001). To monitor such serious adverse events accompanying the YF vaccine, Fiocruz-Biomanguinhos has created a task force, which together with the Health Ministry will be responsible for immunological profile analyses and detection of YF virus as well as any other pathogenic agent that may quite possibly be related to clinical complications presented by the patient, e.g. leptospirosis.

${ }^{+}$Corresponding author: rugimar@bio.fiocruz.br

Received 3 July 2006

Accepted 7 December 2006
With the objective of defining a protocol to analyze blood samples from patients with serious adverse events after YF 17DD vaccination, when the procedure cannot be effected immediately due to sample shipping delays, we have initially studied the influence of the time interval on the lymphocyte subset profiles by flow cytometry using the whole blood lysis method (Loken et al. 1988) and Histopaque gradient sedimentation (Noble et al. 1968). The flow cytometry technique has been successfully employed to enumerate and identify lymphocyte specific sets or subsets from blood specimens after YF vaccination (Santos et al. 2005, Co et al. 2002). $\mathrm{CD} 4^{+} \mathrm{CD} 38^{+} \mathrm{T}, \mathrm{CD} 8^{+} \mathrm{CD} 38^{+} \mathrm{T}, \mathrm{CD} 3^{+} \mathrm{T}, \mathrm{CD} 19^{+} \mathrm{B}$ lymphocyte subsets were analyzed in nine healthy volunteer vaccinees immediately after blood collection (control) and after intervals of 24 and $48 \mathrm{~h}$, following the previous recommended procedures (Mandy et al. 2003, Gratama 2006). All samples were collected in $0.105 \mathrm{M}$ sodium citrate anticoagulant (BD Vacutainer Systems) and stored at room temperature with protection from light. Temperatures above $37^{\circ} \mathrm{C}$ or below $4^{\circ} \mathrm{C}$ might cause cellular destruction and affect flow cytometry measurements (Mandy et al. 2003)

Dual and triple-staining labeled monoclonal antibodies [CD3 (IgG1)-Fluorescein Isothiocyanate (FITC)/ CD19-Phycoerythrin (PE); CD8-PE/CD38-FITC/CD4Phycoerythrin-Cyanine 5 (PC5)] and IgG1-FITC/IgG1$\mathrm{PE}$ isotype control (Immunotech, Beckmann Coulter, Marseille, France) were used. The stained cells were run in an EPICS ALTRA flow cytometer (Beckmann Coulter, Hialeah, FL, US) equipped with an argon ion laser. Ten 
thousand events were obtained and analyzed using the Expo 32 software (Beckmann Coulter). The forward scatter and side scatter profiles distinguished lymphocytes and monocytes. An electronic gate was created around lymphocytes. A multifactor analysis of variance (ANOVA) followed by the least significant difference (LSD) procedure, Statgraphics Plus Version 4.1 Software (US), was applied to evaluate statistically significant differences between means. With this method, there is a 5\% risk of identifying each pair of means significantly different when the actual difference equals 0 . Differences were considered as statistically significant at $p \leq 0.05$.

The results obtained demonstrated that, when the whole blood lysis method was utilized for both time intervals, a significant increase of cellular debris was detected. However this fact did not hamper the detection of lymphocyte subsets using labeled monoclonal antibodies. There was also no significant change in lymphocyte subset percentage during the two time intervals analyzed $\left(\mathrm{CD}^{+} \mathrm{T}\right.$ cells $p=0.6720 ; \mathrm{CD} 19^{+} \mathrm{B}$ cells $p=$
0.1112 (Figs $1 \mathrm{~A}, 2 \mathrm{~A}$ ); $\mathrm{CD} 4^{+} \mathrm{T}$ cells $p=0.861$; $\mathrm{CD} 4{ }^{+} \mathrm{CD} 38^{+} \mathrm{T}$ cells $p=0.7467 ; \mathrm{CD} 8^{+} \mathrm{T}$ cells $p=$ 0.2245 ; $\mathrm{CD}^{+} \mathrm{CD} 38^{+} \mathrm{T}$ cells $p=0.1166$ (Figs $1 \mathrm{~A}, 2 \mathrm{~B}$ ). In contrast, the time interference in lymphocyte subset percentage could be observed when blood samples were processed by Histopaque gradient sedimentation, which resulted in a significant difference from 24 to $48 \mathrm{~h}$ post collection, except for $\mathrm{B}$ cells $\left(\mathrm{CD}^{+} \mathrm{T}\right.$ cells $p<0.0001$; CD19 ${ }^{+} \mathrm{B}$ cells $p=0.1811$ (Figs $1 \mathrm{~B}, 2 \mathrm{~A}$ ); $\mathrm{CD}^{+} \mathrm{T}$ cells $p$ $=0.0001 ; \mathrm{CD}^{+} \mathrm{CD} 38^{+} \mathrm{T}$ cells $p=0.0001 ; \mathrm{CD} 8^{+} \mathrm{T}$ cells $p<0.0001 ; \mathrm{CD}^{+} \mathrm{CD} 38^{+} \mathrm{T}$ cells $p<0.0001$ (Figs 1B, 2B).

The YF 17DD vaccine, produced in FiocruzBiomanguinhos, Brazil, has proved to be a safe and efficient vaccine, providing suitable results regarding neutralizing antibody production (Marchevsky et al. 2003). However, some serious adverse events after vaccination have been reported (Galler et al. 2001, Vasconcelos et al. 2001), supporting the idea of other authors that cellular immune response peculiarities of the host might induce adverse events after YF vaccination (Martin et al. 2001).
A

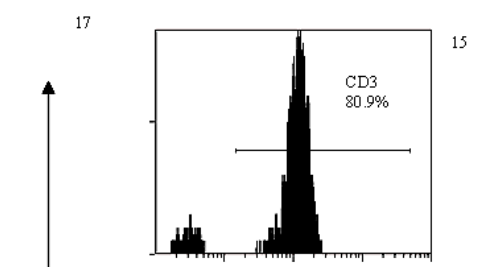

39
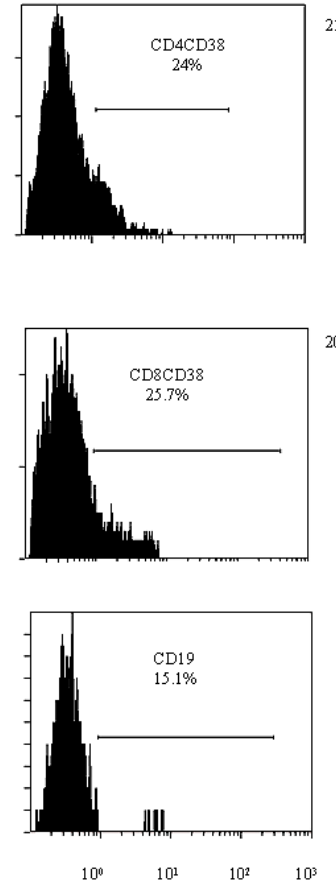

$24 \mathrm{~h}$
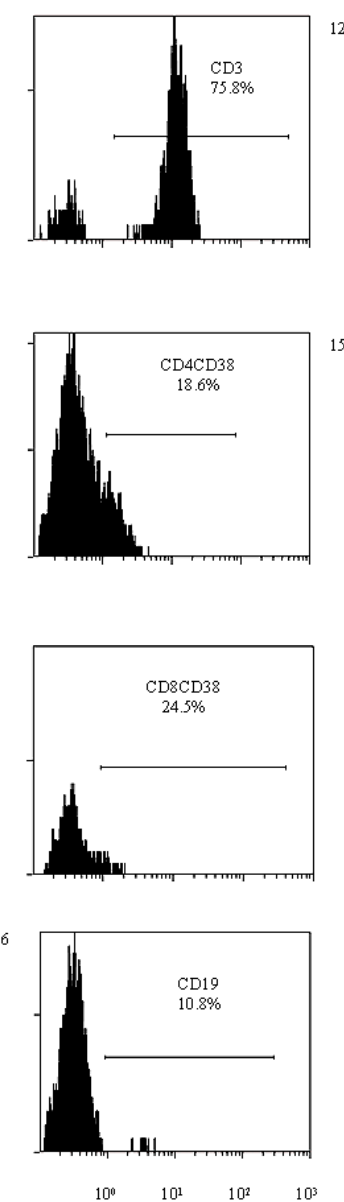

$48 \mathrm{~h}$
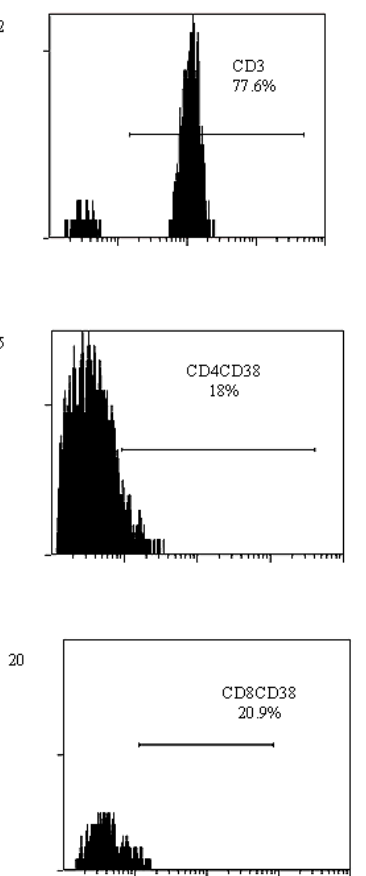

25

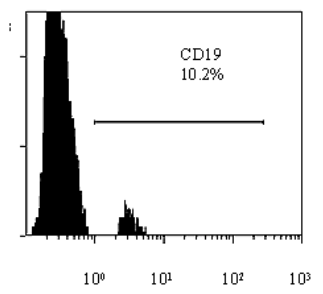

Fluorescence intensity

Fig. 1A: phenotypic analyses of the lymphocyte subsets after dual and triple-stained with CD3-FITC/CD19-PE and CD4-PC5/CD8-PE/CD38-FITC monoclonal antibodies. The histograms represent the percentage of $\mathrm{CD} 3^{+} \mathrm{T}$ cells, $\mathrm{CD} 4^{+} \mathrm{CD} 38^{+} \mathrm{T}$ cells, $\mathrm{CD} 8^{+} \mathrm{CD} 38^{+} \mathrm{T}$ cells, and $\mathrm{CD} 19^{+} \mathrm{B}$ cells analyzed immediately after blood collection (0), 24 and $48 \mathrm{~h}$ later. These samples were processed by whole blood lysis method. 
In this study, the flow cytometry method was chosen to monitor T and B lymphocyte subsets, because it is an efficient tool for definition and quantification of lymphocytes. The typing of lymphocyte subsets may be influenced by a variety of technical specificities, such as sample and lymphocyte preparations, time and storage temperature (Ekong et al. 1993).

We observed in forward and side scatter dot plot lymphocyte subsets at 24 and $48 \mathrm{~h}$ after collection an area of lower definition than that of the control sample with both techniques. The gradient sedimentation by Histopaque was not as efficient as the whole blood lysis method when samples were analyzed $48 \mathrm{~h}$ post-collection.

The results displayed no change in the relative levels of $\mathrm{T}$ and $\mathrm{B}$ cells when whole blood lysis was analyzed at $48 \mathrm{~h}$ post-collection, but a significant change in T lymphocyte subsets as exhibited when these cells were separated by a density gradient. This fact may be due to a weak definition between peripheral blood mononuclear cells and non-nucleated red cell and debries in the gra- dient sedimentation, which can lead to a technical error in the lymphocyte separation from red cell and granulocyte contamination.

In a previous study, Nicholson et al. (1984) reported similar results when they analyzed $\mathrm{T}$ cells in PBMC preparations $24 \mathrm{~h}$ after collection. When PBMC was isolated in a density gradient, these authors observed a change in lymphocyte subset levels in whole blood samples that were stored at room temperature for $24 \mathrm{~h}$ with a significant increase in $\mathrm{T}$ cells and decrease in $\mathrm{B}$ cells. In contrast, we witnessed no significant change in $\mathrm{B}$ and $\mathrm{T}$ cell levels when whole blood samples were stored for $48 \mathrm{~h}$. It is possible that the discrepancies between our findings and theirs are associated with contamination of cellular elements, e.g. neutrophils, nonnucleated red cells, that may take place in blood sample not manipulated immediately after collection.

The data presented herein indicate that when the flow cytometric analysis cannot be carried out immediately, the lysis whole blood method should be adopted to analyze lymphocyte subsets from patients with serious ad-
B
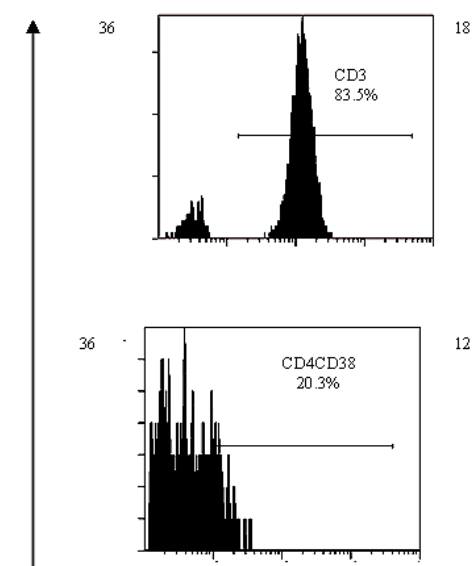

16

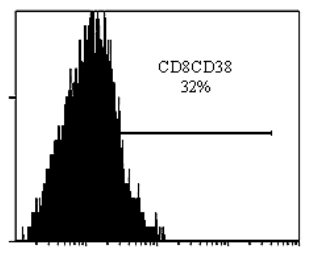

20
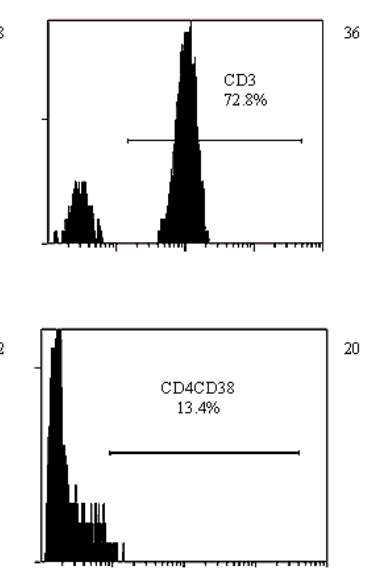

$24 \mathrm{~h}$
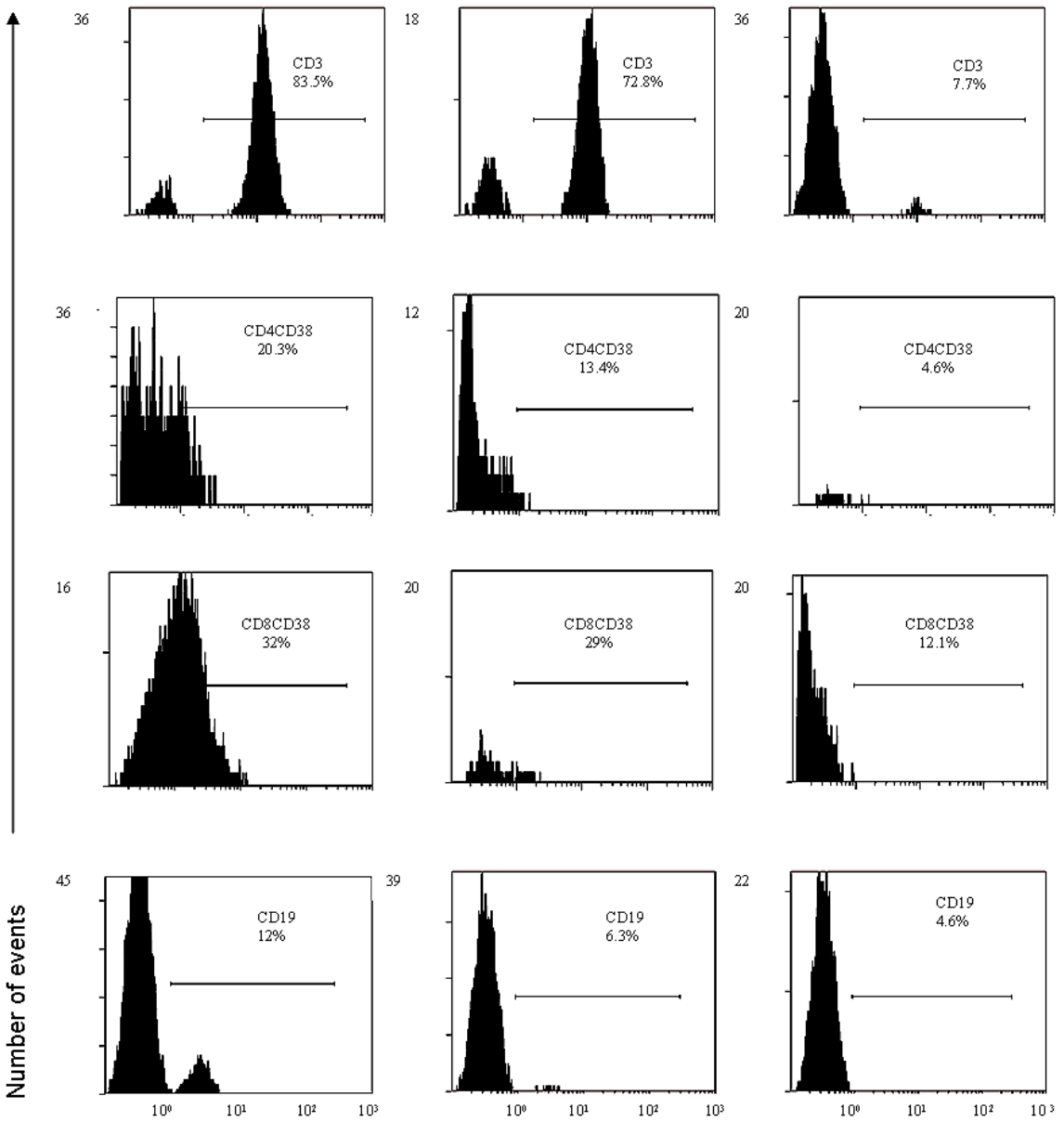

Fluorescence intensity

Fig. 1B: phenotypic analyses of the lymphocyte subsets, isolated in a gradient sedimentation by Histopaque, after dual and triple-stained with CD3FITC/CD19-PE and CD4-PC5/CD8-PE/CD38-FITC monoclonal antibodies. The histograms represent the percentage of CD3 ${ }^{+} \mathrm{T}_{\text {cells, }} \mathrm{CD}^{+} \mathrm{CD} 38^{+} \mathrm{T}$ cells, CD $8^{+} \mathrm{CD} 38^{+} \mathrm{T}$ cells, and $\mathrm{CD} 19^{+} \mathrm{B}$ cells analyzed immediately after blood collection $(0), 24$ and $48 \mathrm{~h}$ later. 
A
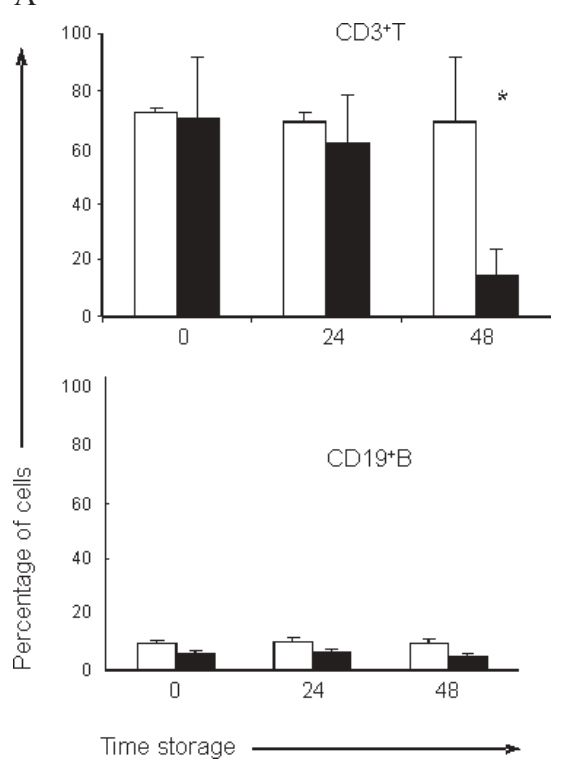

B
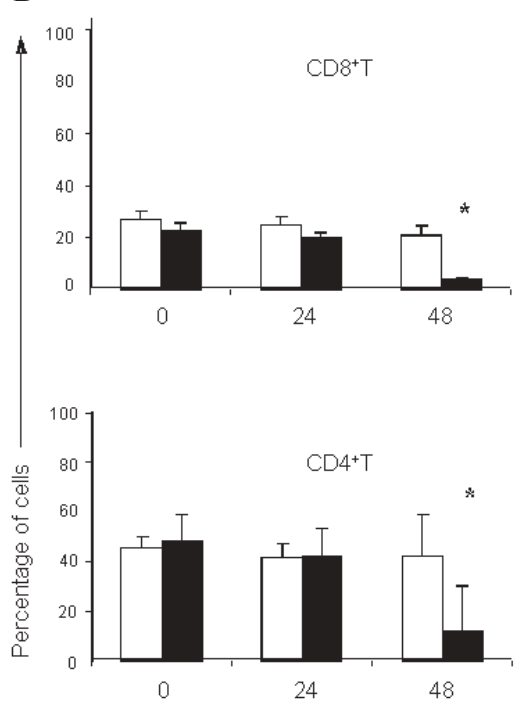

Time storage
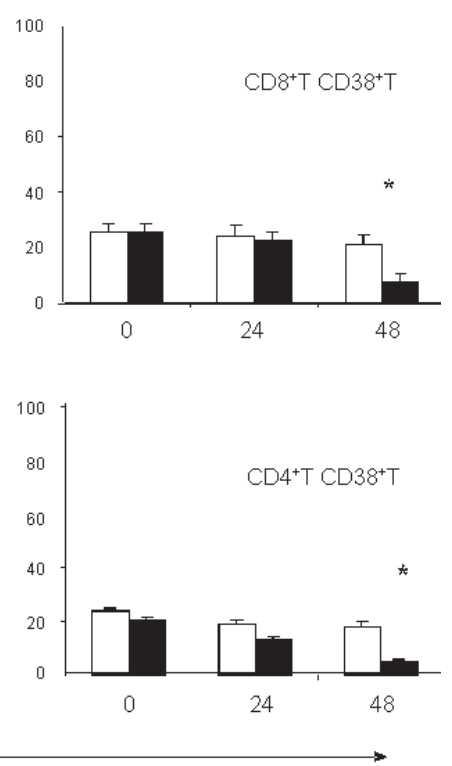

Fig. 2A: the average of $\mathrm{CD}^{+} \mathrm{T}$ and $\mathrm{CD} 19^{+} \mathrm{B}$ cell percentages from peripheral blood of nine healthy volunteers. The bars show the mean of percentage of the lymphocyte subsets analyzed on flow cytometer, immediately after blood collection (control, 0), 24, and $48 \mathrm{~h}$ later. The black bars represent gradient sedimentation by Histopaque, and the white bars represent the whole blood lysis method. * indicates statistically different results between whole blood lysis method and gradient sedimentation by Histopaque. Standard error $( \pm \mathrm{SE}) p<0.05$. Fig. $2 \mathrm{~B}$ : CD $8^{+} \mathrm{T}, \mathrm{CD} 8^{+} \mathrm{CD} 38^{+} \mathrm{T}, \mathrm{CD} 4^{+} \mathrm{T}$, $\mathrm{CD}^{+} \mathrm{CD} 38^{+} \mathrm{T}$ cells percentages from PBMC from peripheral blood of nine healthy volunteers. The bars show the mean of percentage of the lymphocyte subsets analyzed on flow cytometer, immediately after blood collection (control, 0 ), 24 , and $48 \mathrm{~h}$ later. The black bars represent gradient sedimentation by Histopaque, and the white bars represent the whole blood lysis method. * indicates statistically different results between whole blood lysis method and gradient sedimentation by Histopaque. Standard error $( \pm \mathrm{SE}) p<0.05$.

verse events after 17DD vaccination. This method can reduce variation over time on lymphocyte subset levels in the immunophenotyping, approximating results obtained with samples analyzed immediately after collection.

\section{REFERENCES}

Co MDT, Terajima M, Cruz J, Ennis FA, Rothman AL 2002. Human cytotoxic $\mathrm{T}$ lymphocyte responses to live attenuated 17D yellow fever vaccine: identification of HLA-B35-restricted CTL epitopes on nonstructural proteins NS1, NS2b, NS3, and the structural protein E. Virology 293: 151-163.

Ekong T, Kupek E, Hill A, Clark C, Davies A, Pinching A 1993. Technical influences on immunophenotyping by flow cytometry. The effect of time and temperature of storage on the viability of lymphocyte subsets. J Immunol Meth 164: 263-273.

Galler R, Pugachev KV, Santos CLS, Ocran SW, Jabor AV, Rodrigues SG, Marchevsky RS, Freire MS, Almeida LFC, Cruz ACR, Yamamura AMY, Rocco IM, Travassos da Rosa ES, Souza LTM, Vasconcelos PFC, Guirakhoo F, Monath, TP 2001. Phenotypic and molecular analyses of yellow fever $17 \mathrm{DD}$ vaccine viruses associated with serious adverse events in Brazil. Virology 290: 309-319.

Gratama JW 2006. Enumeration of immunologically defined cell populations by flow cytometry; approved guideline, 2 nd ed., NCCLS document H42, A2.

Loken MR, Meiners H, Terstappen LWM 1988. Comparison of sample preparation techniques for flow cytometric analysis of immunofluorescence. Cytometry (Suppl.II): 53.

Mandy FF, Nicholson JKA, McDougal JS 2003. Guidelines for performing single-platform absolute CD4+ T-cell determinations with CD45 gating for persons infected with human immunodeficiengy virus. MMWR 52 (RR02): 1-13.

Marchevsky RS, Freire MS, Coutinho ESF, Galler R 2003. Neurovirulence of yellow fever 17DD vaccine vírus to rhesus monkeys. Virology 316: 55-63.

Martin M, Tsai TF, Gropp B, Chang G-JJ, Holmes DA, Tseng J, Shieh W-J, Zaki SR, Al-Sanouri I, Cutrona AF, Ray G, Weld LH, Cetron MS 2001. Fever and multisystem organ failure associated with 17D-204 yellow fever vaccination a report of four cases. Lancet 358: 98-104.

Nicholson JKA, Jones BM, Cross GD, McDougal JS 1984. Comparison of T and B cell analyses on fresh and aged blood. $J$ Immunol Meth 73: 29-40.

Noble PB, Cuttis JH, Carroll KK 1968. Ficoll flotation for the separation of blood leukocyte types. Blood 31: 66-73.

Santos AP, Bertho AL, Dias DC, Santos JR, Marcovistz R 2005. Lymphocyte subset analyses in healthy adults vaccinated with yellow fever 17DD virus. Mem Inst Oswaldo Cruz 100: 331-337.

Vasconcelos PFC 2003. Febre amarela. Rev Soc Bras Med Trop 36: 1-29.

Vasconcelos PFC, Luna EJ, Galler R, Silva LJ, Coimbra TL, Barros VLRS, Monath TP, Rodrigues SG, Laval C, Costa ZG, Vilela MFG, Santos CLS, Papaiordanou CMO, Alves VAF, Andrade LD, Sato HK, Rosa EST, Froguas GB, Laçava E, Almeida LMR, Cruz ACR, Rocco IM, Santos RTM, Oliva OFP 2001. Brazilian Yellow Fever Vaccine Evaluation Group. Serious adverse events associated with yellow fever 17DD vaccine in Brazil: a report of two cases. Lancet 358: 91-97. 